\title{
Intralobar Sequestration of Right Lung: An Unusual Presentation
}

\author{
Manoj Kumar Pandey, Hemant Kumar, Preeti Gupta ${ }^{1}$ \\ Department of Respiratory Medicine, Dr. Ram Manohar Lohia Institute of Medical Sciences, Lucknow, 'Department of Ophthalmology, \\ Hind Institute of Medical Sciences, Sitapur, Uttar Pradesh, India
}

\section{Abstract}

Bronchopulmonary sequestration (BPS) is a rare congenital disorder of the lung. It consists of a nonfunctioning lung tissue that is not normally connected with the tracheobronchial tree and receives its blood supply from systemic circulation. The presentation of sequestration is variable, ranging from asymptomatic to more severe symptoms such as massive hemoptysis, resulting in increased mortality and morbidity. Although BPS commonly involves left lower airway, here we report the case of a 17-year-old female who presented with recurrent hemoptysis and was eventually diagnosed with pulmonary sequestration in the right lower lobe, an unusual presentation of intralobar sequestration.

Keywords: Bronchopulmonary sequestration, computed tomography pulmonary angiography, video-assisted thoracic surgery

\section{INTRODUCTION}

Bronchopulmonary sequestration (BPS), also called pulmonary sequestration, is a rare congenital anomaly of the lung. It consists of a nonfunctioning mass of pulmonary tissue with airway and alveolar elements, that lacks normal communication with the tracheobronchial tree and receives its arterial blood supply from the systemic circulation. ${ }^{[1]}$ Congenital abnormalities of the lung are rare, found in approximately 1 in 10,000-35,000 live births. ${ }^{[2]}$ Among these, the most common is congenital pulmonary airway malformation, while BPS represents only $0.15 \%-6.40 \% .^{[3]}$ Anatomically, BPS is classified into intralobar sequestration (ILS) and extralobar sequestration (ELS). ILS is overall the most common form, comprising approximately $75 \%-90 \%$ of sequestrations, whereas ELS constitutes about 10\%-25\%. Nearly $60 \%$ of ILS are located in the posterior basal segment of the left lower lobe. ${ }^{[4]}$ Here, we present a case of right lower lobe ILS presenting as recurrent lung abscess.

\section{Case Report}

A 17-year-old female patient presented to our hospital with complaints of streaky hemoptysis, fever, and cough with expectoration for the last 15 days. There was a history of similar illness 3 months prior, for which she was treated with

\begin{tabular}{|l|l|}
\hline \multicolumn{2}{|c|}{ Access this article online } \\
\hline Quick Response Code: & Website: \\
\hline & www.ijrc.in \\
& \\
& \\
\end{tabular}

broad-spectrum antibiotics and got relieved. There was no history of antitubercular therapy in the past. General physical examination was within normal limits. Microbiological examination of sputum for acid-fast bacilli, GeneXpert, and Gram stain was negative. Chest radiograph posteroanterior view showed heterogeneous opacity, with two cavities containing air-fluid level in the right lower zone suggestive of lung abscess [Figure 1]. A chest X-ray taken 3 months prior showed a similar type of lesion in the right lower zone. Contrast-enhanced computed tomography (CT) scan thorax revealed evidence of multiple cysts in the basal segments of the lower lobe of the right lung with air-fluid level in a few of them [Figure 2]. As the lesion was recurrent and involved the same lobe, the patient was advised for CT pulmonary angiography to rule out bronchovascular anomaly. Angiography revealed multiple cystic lesions in the basal segment of the right lower lobe with arterial supply from the abdominal aorta at the

Address for correspondence: Dr. Hemant Kumar, Department of Respiratory Medicine, Dr. Ram Manohar Lohia Institute of Medical Sciences, Vibhuti Khand, Gomti Nagar, Lucknow, Uttar Pradesh, India. E-mail: drhemantkumar14@gmail.com

This is an open access journal, and articles are distributed under the terms of the Creative Commons Attribution-NonCommercial-ShareAlike 4.0 License, which allows others to remix, tweak, and build upon the work non-commercially, as long as appropriate credit is given and the new creations are licensed under the identical terms.

For reprints contact: WKHLRPMedknow_reprints@wolterskluwer.com

How to cite this article: Pandey MK, Kumar H, Gupta P. Intralobar sequestration of right lung: An unusual presentation. Indian J Respir Care 2021;10:143-5.

Received: 01-07-2020 Revised: 09-08-2020 Accepted: 07-09-2020 Published: 31-01-2021 
level of D12 and L1 vertebrae [Figure $3 \mathrm{a}$ and $\mathrm{b}$ ]. The diagnosis of intralobar pulmonary sequestration was made.

\section{Discussion}

BPS is a rare congenital anomaly of the lower airway. The most widely accepted embryologic theory is that sequestration originates in the pseudoglandular stage of development of the

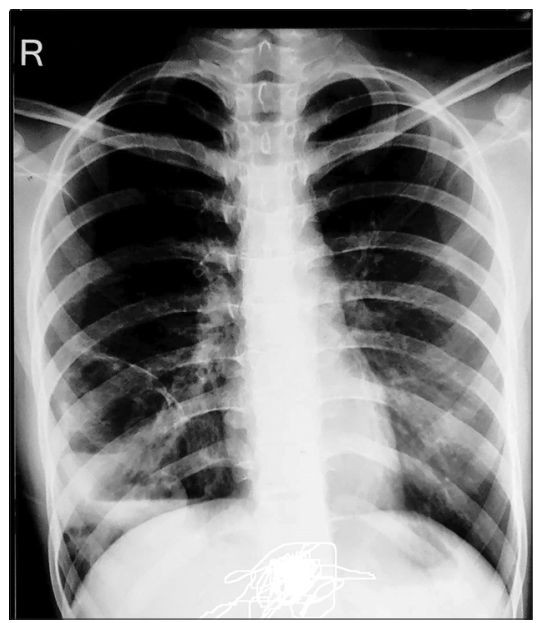

Figure 1: Chest radiograph posteroanterior view showing heterogeneous opacity with two cavities containing air-fluid level in the right lower zone

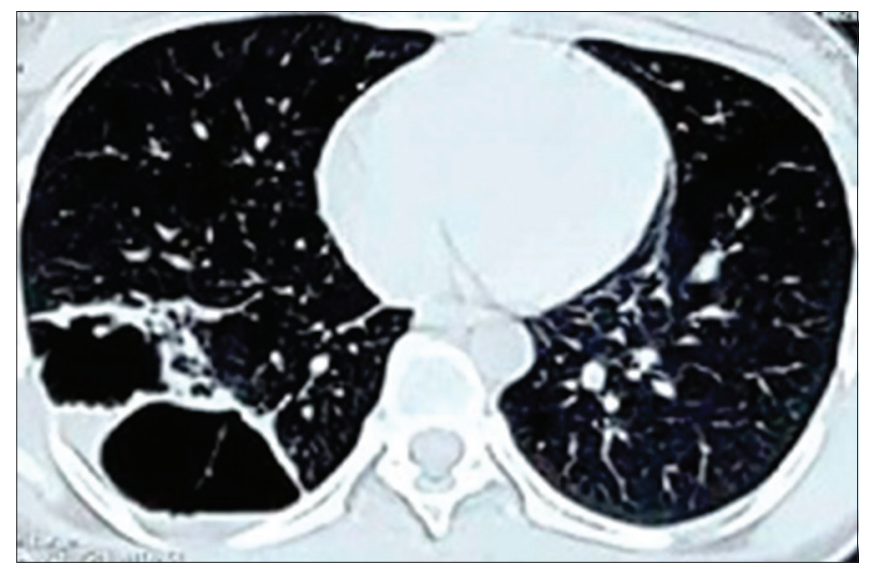

Figure 2: Computed tomography scan thorax lung showing cystic lesions in the basal segments of the lower lobe of the right lung with air-fluid level in a few of them

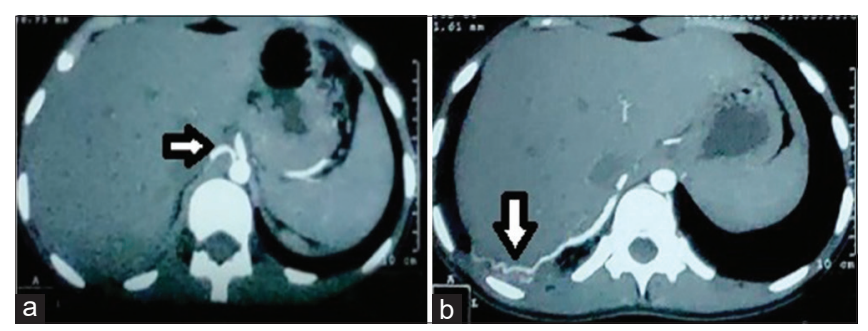

Figure 3: Computed tomography pulmonary angiography of the patient showing: (a) an anomalous systemic artery coming out from the abdominal aorta. (b) Sequestrated part of the lung along with its arterial supply lung (between 5 and 17 weeks of gestation), before the division of aorta and pulmonary circulation. ${ }^{[5]}$ The ILS is located in the normal lobe and lacks its visceral pleura, whereas the ELS is located outside the normal lung and has its own visceral pleura. More than $90 \%$ of sequestrations are located in the lower lobe, with 2-3 times more common in the left lower lobe than the right. ${ }^{[6]}$ In this patient, the sequestration was located in the right lower lobe. The sequestrated lung receives its blood supply from the systemic circulation, most commonly the thoracic or abdominal aorta, and drains into the pulmonary veins, azygos vein, hemiazygos vein, inferior vena cava, or right atrium. ${ }^{[7]}$ In this patient, the sequestrated part receives its arterial supply from the abdominal aorta.

The most common presentation of ILS after the neonatal period is recurrent lung infection with symptoms such as fever, cough, and sometimes hemoptysis or chest pain. Patients with ELS are unlikely to develop infection. Plain chest radiograph is usually nonspecific, showing consolidation that mimics pneumonia, or shows a solitary soft-tissue mass or nodule, or a cystic lesion with or without air-fluid level. On CT thorax, the ILS may manifest as a mass lesion, a cystic lesion that may be filled with fluid, air, or both. CT pulmonary angiography is the gold standard for diagnosis of BPS as it confirms the anatomy, identifies the arterial supply, and shows the venous drainage. ${ }^{[8]}$

The treatment of choice for BPS is surgical resection to avoid infection and damage to the lung parenchyma. Surgery is recommended even in asymptomatic patients to avoid the risk of life-threatening complications such as massive hemoptysis. Surgery usually involves lobar resection through standard thoracotomy or video-assisted thoracic surgery. During lobectomy, it is important to ligate carefully the aberrant systemic artery. This artery is very fragile and can get easily transected, if ligated roughly. If it gets transected, the artery retracts into the abdomen, and this may lead to increased perioperative complications.

\section{Declaration of patient consent}

The authors certify that they have obtained all appropriate patient consent forms. In the form, the parent has given his consent for the images and other clinical information to be reported in the journal. The parent understands that his daughter's name and initial will not be published, and due efforts will be made to conceal her identity, but anonymity cannot be guaranteed.

\section{Financial support and sponsorship}

Nil.

\section{Conflicts of interest}

There are no conflicts of interest.

\section{REFERENCES}

1. Landing BH, Dixon LG. Congenital malformations and genetic disorders of the respiratory tract (larynx, trachea, bronchi, and lungs). Am Rev Respir Dis 1979;120:151-85. 


\section{Pandey, et al.: An unusual right-sided sequestration of lung}

2. Durell J, Thakkar H, Gould S, Fowler D, Lakhoo K. Pathology of asymptomatic, prenatally diagnosed cystic lung malformations. J Pediatr Surg 2016;51:231-5.

3. Van Raemdonck D, De Boeck K, Devlieger H, Demedts M, Moerman P, Coosemans W, et al. Pulmonary sequestration: A comparison between pediatric and adult patients. Eur J Cardiothorac Surg 2001;19:388-95.

4. Savic B, Birtel FJ, Tholen W, Funke HD, Knoche R. Lung sequestration: Report of seven cases and review of 540 published cases. Thorax 1979;34:96-101.
5. Correia-Pinto J, Gonzaga S, Huang Y, Rottier R. Congenital lung lesions - Underlying molecular mechanisms. Semin Pediatr Surg 2010;19:171-9.

6. Wei Y, Li F. Pulmonary sequestration: A retrospective analysis of 2625 cases in China. Eur J Cardiothorac Surg 2011;40:39-42.

7. Andrade CF, Ferreira HP, Fischer GB. Congenital lung malformations. J Bras Pneumol 2011:37:259-71.

8. Lin CH, Lin CT, Chen CY, Phen HC, Chen HC, Wong PY. Pulmonary sequestration. Chin Med J (Taipei) 1994;53:168-72. 